\title{
Instituição de herdeiro por via de legado dos remanescentes
}

\author{
Dr. Noé Azevedo
}

\begin{abstract}
- Não havendo nư proprietario no momento da abertura da successão, nem fideicommissario com existencia e capacidade para receber a herança no momento da abertura da substituição, entende-se que a verba testamentaria não institue usofructo nem fideicommisso, valendo o seu dispositivo apenas como clausula de inalienabilidade vitalicia dos bens legados.

- Sendo o testamenteiro um auxiliar do juizo na execução do testamento, deve ser afastado do encargo pelos mesmos motivos de incompatibilidade e suspeição que impediriam o juiz de desempenhal-o.
\end{abstract}

\section{P A R E C E R}

\section{1. ${ }^{a}$ Pergunta:}

- A' vista das disposições testamentarias supra transcriptas fielmente, sobretudo da referente ao remanescente dos bens, póde considerar-se a herança como tendo sido, de completo, na sua totalidade, distribuida em legados?

A' vista das disposições testamentarias e dos principios do nosso direito successorio, póde-se affirmar, sem a mini- 
ma dúvida, que a mulher do testador, além de ser distinguida como legataria, foi expressamente instituida herdeira do mesmo. E herdeira já o era, na falta de ascendentes ou descendentes, por força do art. $1.603 \mathrm{n}$. III do Codigo Civil.

"O que caracteriza a instituição de herdeiro, é o facto de succeder elle em todos OU NOS REMANESCENTES dos bens, ou numa quota delles, ainda que assignalada em certa proporção como $1 / 2,1 / 3,1 / 4,1 / 5$, etc.; exemplo: Deixo a Primus todos os meus bens, OU OS REMANESCENTES dos meus bens (depois da distribuição dos legados) ou a metade, a terça parte, ou a quarta parte, ou a quinta parte dos meus bens, etc.;

o que caracteriza a instituição de legatario é o facto de receber elle determinada cousa, ou certo e determinado valor, como por exemplo: Deixo a Primus a minha casa tal (objecto determinado), ou os bens immoveis situados em tal logar (certa e determinada parte de bens, ou um cavallo, cousa sem individuação, mas determinada em certo genero), ou finalmente, um cavallo arabe, cousa sem individuação mas determinada em certa especie" (Itabaiana de Oliveira, "Dir. das Successões", 2." ed., pags. 32/33).

Teixeira de Freitas considerava como rustico esse modo de instituir herdeiro, legando-lhe os remanescentes; mas reconhecia expressamente que o legatario de taes remanescentes era herdeiro instituido e não simples legatario. ("Testamentos e Successões", ed. de 1881, pag. 37).

Ora, o que está escripto na clausula 4. ${ }^{2}$ do testamento é que deduzidos os legados, ficaria o remanescente para a mulher do testador. Na passagem citada, Teixeira de Freitas mostra que sendo o remanescente ás vezes tão pouco, ficavase na dúvida sobre ser o seu titular um herdeiro que pudesse ser obrigado pelos credores.

Mas, no caso, essa dúvida não teria procedencia. 0 testador fez determinações expressas no sentido de que esse remanescente viesse a ser representado pelo melhor de sua herança, isto é, pelas acções da Companhia Alpha e Beta. 
Assim é que, para não desvalorizar esse remanescente, para não tocar nessas acções, determinou que fossem rateados os legados, se os outros bens do Espolio não déssem para pagal-os sem tocar nessas acções.

Desse modo evidencia-se que sendo legataria de um remanescente constituido pela melhor e talvez maior parte da herança, e esposa do "de cujus", que já era sua herdeira "ex vi legis" foi expressamente instituida sua herdeira universal.

\section{2. ${ }^{a}$ Pergunta :}

- A ultima disposição ou clausula (a referente ao remanescente) compendia simples instituição de um legado, ou é verdadeira instituição de herdeiro?

Demonstrando na resposta anterior que a herança não foi toda distribuida em legados, já ficou demonstrado que o legado do remanescente representa um verdadeira instituição da esposa por herdeira universal do testador.

\section{3. ${ }^{a}$ Pergunta:}

- Qual a verdadeira situação da viuva, fosse embora o da separação o regime do casamento? E', ou não, ella, simultaneamente, herdeira legitima (Cod. Civil, art. 1.603, III) e herdeira testamentaria (tenha-se em vista a ultima disposição referente ao remanescente dos bens), além de legataria e usofructuaria ou herdeira fiduciaria, como, nos autos do inventario houve por bem opinar o Curador ou Promotor de Residuos?

Como já ficou dito, a mulher do testador, além de herdeira legitima por força do art. 1.603, III do Codigo Civil, foi distinguida com varios legados e instituida herdeira do 
"de cujus", por força do legado de todo o remanescente, a ser constituido pela melhor parte da herança, segundo a estimação do proprio testador, revelada pelo cuidado com que procurou evitar a alienação das acções das Companhias Alpha e Omega, que viriam a constituir esse remanescente:

\section{4. ${ }^{a}$ Pergunta :}

- A disposição testamentaria referente ao remanescente dos bens instituiu um usofructo ou um fideicommisso?

- Trata-se de uma ou outra coisa, é ou não juridicamente nulla aquella disposição? já por contrária aos dispositivos legaes que regem ambos os institutos, já por terem ficado as determinações nella contidas subordinadas aos desejos de ultima vontade da usofructuaria ou fiduciaria (De não se esquecer que não contém a disposição ou clausula qualquer referencia ao nú proprietario e não existem os fideicomissarios)?

A disposição testamentaria em apreço não instituiu usofructo nem fideicomisso. Estabeleceu providencias para que a viuva conservasse durante toda a sua existencia o remanescente da herança a ser constituido pelas acções das Companhias Alpha e Omega, que ficaram sujeitas á clausula de inalienabilidade, nos termos dos artigos 1.676 e 1.723 do Codigo Civil.

"De tres maneiras distinctas póde o testador conseguir que as utilidades effectivas de determinado bem aproveitem ao legatario por toda sua vida, sem o risco de dissipações :

a) E'-lhe facultado, em primeiro logar, deixar ao beneficiado apenas o usofructo do objecto legado, nomeando no mesma acto o nú proprietario, a quem compete a propriedade plena após a morte daquelle; 
b) Permitte-lhe, em segundo lugar, a lei que estabeleça uma substituição fideicommissaria, cabendo a propriedade da coisa ao primeiro legatario durante toda a sua vida, como fiduciario, com a obrigação de conserval-a e encargo de entregal-a a outrem, o fideicommissario, por occasião de sua morte;

c) Tem, finalmente, o direito de gravar o legado com a clausula de inalienabilidade vitalicia, de onde resulta ser o legatario proprietario da coisa, mas sem a faculdade de transferil-a de seu patrimonio, durante toda a sua existencia.

Variam os institutos, diversificam os respectivos conteúdos, restringem-se ou alargam-se os direitos dos beneficiados, mas, em qualquer delles, se obtem o objectivo visado - assegurar a determinada pessôa por toda a existencia os fructos e utilidade de certos bens". - (EDUARDO ESPINOLA, "Questões Juridicas e Pareceres", pag. 423).

E' evidente que a disposição testamentaria analysada, embora falle em usofructo, não contém uma instituição ou legado de usofructo.

Não houve a nomeação simultanea de nú proprietario. E sem a coexistencia dessas duas personalidades é impossivel constituir-se um usofructo no sentido technico e legal dessa expressão.

Tambem não foram satisfeitos os requisitos essenciaes do fideicommisso.

Havendo no fideicommisso dois herdeiros successivos, diz CLOVIS BEVILAQUA que - "a capacidade do fiduciario deve existir no momento da morte do testador, ou seja da abertura da successão, e a do fideicommissario no momento da abertura da substituição" (Annot. ao art. 1.733 do Codigo Civil).

Ora, na verba testamentaria em questão não se nomeou um fideicommissario, que no momento da abertura da substituição, isto é, na occasião da morte da viuva, tivesse capacidade para succeder por testamento, nos termos do art. 1.717 do Cod. Civil. 
Dispõe esse texto que "podem adquirir por testamento as pessôas existentes ao tempo da morte do testador, que não forem por este codigo declaradas incapazes".

Assim como o art. 1.718 admitte que a prole eventual, embora inexistente ao tempo da morte do testador, possa adquirir por testamento, poderiamos admittir que as fundações de que fala o testador pudessem receber o legado dos remanescentes na qualidade de fideicommissarias.

Mas, para isso seria indispensavel que o testador tivesse providenciado para que as taes fundações se constituissem logo após á sua morte, adquirindo a existencia e personalidade necessarias para adquirirem os bens "no momento da abertura da substituição", segundo o ensinamento de CLOVIS.

Mas o testamento, em vez de providenciar sobre a organisação dessas fundações durante a vida da supposta fiduciaria, para estarem habilitadas, com existencia e capacidade plenas, para substituil-a quando da sua morte, somente cogitou de organizal-as depois de fallecida a viuva.

Nessas condições, é evidente que no momento da abertura da substituição não haverá fideicommissario, não existirá uma personalidade que tenha capacidade para receber a herança.

Assim como é indispensavel no usofructo a cooexistencia de usofructuario e nú proprietario no momento da abertura da successão, é absolutamente necessaria a existencia do fideicommissario no momento em que se deve operar a substituição.

Do contrário iriamos cahir no instituto da herança jacente, expressamente abolido pelo Codigo Civil art. 1.572 - sempre que ha conjuge, herdeiro ou testamento (art. 1.591). - Medindo-se bem o alcance das determinações do testador sobre as fundações a serem organizadas depois da morte da mulher, para receberem o remanescente da herança, attribuido a esta, vê-se que taes disposições são tendentes a regular a herança da mulher e não a do testador. E elle proprio teve o presentimento de estar invadindo esphera 
alheia, de estar testando por sua mulher, de estar regulando a successão della e não a sua, quando determinou que fossem "respeitados quesquer desejos de ultima vontade", da sua então viuva.

Assim sendo, evidencia-se a nullidade dessas determinações, que não se referem á herança do testador e sim á successão de sua viuva.

$O$ unico effeito que se póde attribuir á clausula testamentaria sobre o remanescente é o determinativo da inalienabilidade dos bens constitutivos desse remanescente durante a vida da mulher do testador, instituida herdeira do mesmo.

\section{5. ${ }^{a}$ Pergunta:}

- A' vista dos termos do testamento, e em face dos dispositivos dos arts. 1572, $1579 \S 3 .^{\circ}, 1591,1592$ e 1754 do Codigo Civil, em que as referencias a conjuge são irrestrictas, sem qualquer cogitação do regime de bens, poderá ou póde, qualquer dos testamenteiros investir-se no cargo de inventariante da herança, com fundamento nos arts. 1755 e 1769 do mesmo Codigo, ou cabe o direito de exercer esse cargo exclusivamente á viuva, dada a circumstancia de, ademais dessa, ter ella, ainda, a qualidade de herdeira legitima e herdeira testamentaria, accrescida da de ter sido, pelo testador, considerada depositaria da sua confiança?

Demonstrado, como ficou, na resposta á primeira pergunta, que o testador não distribuiu toda a herança em legados, e que a viuva, além de herdeira legitima, ex-vi do art. $1.603 \mathrm{n} .^{\circ}$ III do Codigo Civil, foi tambem instituida herdeira do "de cujus", por força do legado de todo o remanescente, nenhuma applicação póde ter, no caso, o art. 1.769 do Codigo Civil. Este artigo sómente attribúe ao testamenteiro as funcções de cabeça de casal se o testador houver 
distribuido toda a herança em legados. E além disso deve ser combinado com o art. 1.754, que sómente dá a posse e administração da herança ao testamenteiro, se não houver conjuge ou herdeiros necessarios, sem fazer qualquer distincção quanto ao regime de bens. Assim, qualquer que seja o regime de bens, o conjuge sobrevivente, herdeiro por força de lei e do testamento, tem incontestavel direito ao cargo de inventariante, não podendo ser excluido por qualquer dos testamenteiros.

\section{Pergunta:}

- Tendo renunciado aos respectivos cargos o segundo $e$ o terceiro testamenteiros ”óde o quarto testamenteiro ser investido no cargo $e$ admittido a assignar o necessario termo de compromisso, não obstante opposição formal da viuva, herdeira $e$ legataria, - hoje no exercicio do cargo de inventariante, a que renunciou o primeiro testamenteiro, que, nesse cargo se investira, na ausencia della na Europa, onde fôra acompanhar o corpo de seu fallecido marido - opposição fundada:

a) - no facto de ser aquelle quarto testamenteiro devedor ao espolio de avultada quantia, sendo a divida provada por conta-corrente, extrahida dos livros commerciaes da firma, de que fôra socio o "de cujus" e de que é socio-gerente o primeiro testamenteiro, que a forneceu, por elle firmada;

b) - no facto de ser o referido quarto testamenteiro inimigo declarado da viuva, herdeira e legataria; $e$

c) - no facto de ter sido o referido quarto testamenteiro falso amigo do "de cujus", pois, além de o haver explorado desde longa data, ainda pouco tempo antes do seu fallecimento, imiscuiu-se em seus nego- 
cios, causando-lhe, assim, como ao seu espolio, avultados prejuizos?

Diz muito bem Tito Prates que "o testamenteiro exerce um encargo; é um auxiliar do Juizo. Quem verdadeiramente cumpre a vontade do testador é o Poder Judiciario, precipuamente pelos seus orgams jurisdiccionaes".

"Nessa missão é o juiz, auxiliado pelo Ministerio Publico, - curadores de orphams e promotores de residuos e pelos auxiliares do Juizo - escrivães, testamenteiros, etc. - E' o juiz quem interpreta as disposiçōes testamentarias. $O$ encargo de testamenteiro traduz-se na incumbencia que este recebe do testador, ou do juiz, de cumprir as disposições testamentarias, ou melhor, de auxiliar o Juizo nesse cumprimento" ("Successão Testamentaria", pags. 328/9).

A nossa legislação não cogita das incompatibilidades e suspeições quanto ao exercicio desse encargo. Mas, considerado o testamenteiro como auxiliar do Juizo, na execução do testamento, deve esse auxiliar ser arredado do cargo pelas mesmas razões de incompatibilidade e suspeição que afastariam o proprio Juiz. Segundo a nossa lei de organização judiciaria - dec. n. 123 , de 1892 - não poderia funccionar como executor do testamento o juiz que fosse inimigo da viuva e inventariante que é uma das partes na causa ou processo, que litigasse com a mesma, ou que tivesse particular interesse no feito. Sería absurdo que por esses motivos não pudesse funccionar o juiz como executor principal e funccionasse o testamenteiro como auxiliar da execução, carregado com esses e outros motivos de suspeição.

Que confiança poderia ter o juiz em semelhante auxiliar?

Demais, deve-se na execução dos testamentos procurar as soluções que melhor assegurem a observancia da vontade do testador (Cod. Civil, art. 1.666). Se o testador conhecesse todos os factos attribuidos ao testamenteiro em questão, infallivelmente revogaria a sua nomeação. Impossibilitado de pronunciar essa revogação, compete ao juiz supprir-lhe 
a vontade. $\mathrm{E}$ a simples leitura do testamento mostra que todo elle constitue uma tocante homenagem á esposa do testador. Ella é a figura central de todas as suas disposições. Qualquer conflicto entre a viuva e o testamenteiro seria infallivelmente resolvido a favor da mesma pelo testador, se elle pudesse manifestar-se.

Cabe ao juiz, em razão do seu officio, providenciar sobre a execução do testamento, de modo a assegurar a execução a mais completa da vontade explicita e implicita do testador, á vista dos termos do testamento.

$\mathrm{E}$ essa vontade está manifesta no seguinte topico do testamento: "Peço aos mesmos (aos testamenteiros) que, como prova de amizade, acceitem a incumbencia na ordem marcada, sempre dois conjunctamente, sendo preciso que os papeis de responsabilidade tenham duas assignaturas.

"Se por fallecimento ou outra causa, desapparecer um dentre elles, os sobreviventes ou restantes, por combinação mutua e com annuencia de minha viuva, convidarão substituto idoneo, o qual será confirmado pelo M. Juiz, e entrará em ultimo".

Ahi está a investidura no cargo de testamenteiro, subordinada á annuencia da viuva.

Providenciando sobre a continuação dos negocios de uma das sociedades de que fazia parte, declarou o testamenteiro e socio J. F. com annuencia e combinação com minha mulher, então viuva, continue a minha firma commercial, etc."

Se o "de cujus" deixou de nomear sua mulher para primeira testamenteira "para lhe poupar trabalho e não por falta de confiança", como expressamente declarou no testamento, constituiu-a, entretanto, ou melhor, investiu-a da dignidade de arbitro supremo de todas as graves questões que surgissem na execução do testamento.

Assim sendo, deante das arguições feitas pela viuva em face do conflicto manifesto de interesse entre o referido testamenteiro e o Espolio, não póde o juiz deferir o compromissa a esse auxiliar, para coadjuval-o na execução do tes- 
tamento. A esse compromisso faltariam as condições essenciaes de probidade e sinceridade da parte do testamenteiro que, procurando assumir o encargo, apesar da opposição da viuva, daria provas irrecusaveis de estar agindo por espirito de emulação ou com o objectivo de defender os proprios interesses contra os do Espolio.

São Paulo, abril de 1935.

N. da R. - Respeitada a ortografia do autor. 